\title{
Student Perceptions of Microblogging: Integrating Twitter with Blogging to Support Learning and Interaction
}

\author{
Brian Thoms \\ SUNY Farmingdale, Farmingdale, NY, USA
}

Brian@BrianThoms.com

\section{Executive Summary}

Social networking technologies are used by millions of individuals around the globe to foster dialogue and share all types of information. It is therefore common to see that campuses abound with students embracing these technologies, sharing everything from personal experiences to general interests and current events with their immediate and extended social circles. Unfortunately, the adaptation of institutional course management system (CMS) software has not been so progressive, and the inclusion of these popular and powerful technologies, which have the potential to foster learning and interaction from a social context, remain somewhat absent from popular CMS platforms, such as Blackboard and Angel.

An objective of Design Science Research (DSR) is to develop technology-based solutions for important and relevant problems. Based on the principles of DSR, we developed software that integrated social technologies into CMS platforms, and the result of our DSR study is the design, construction, and implementation of a comprehensive online learning community (OLC) that integrates microblogging with traditional blogging. As a result, students now have the ability to use their personal Twitter accounts to bring new information into the course OLC, where they can extend the conversation through more traditional blogging and blog commenting features, which have shown great success in fostering learning and social interaction within an OLC. Our software design carefully reflects our theoretical model, which includes theories of Constructivism, Social Presence Theory, and Activity Theory. Each theory offers important guidelines for how individuals use technology to learn and interact within an OLC environment.

To measure the impact of our software, we implemented the OLC across upper-division undergraduate courses in information systems with the goal of fostering higher levels of learning and social interaction. The results show that students' experience microblogging was positive and the software helped to foster information sharing and information exploration. From a design perspective, we discovered that directly integrating microblogging with traditional blogging with our OLC did not result in a system that was "more than the sum of the parts," although it did result in

Material published as part of this publication, either on-line or in print, is copyrighted by the Informing Science Institute. Permission to make digital or paper copy of part or all of these works for personal or classroom use is granted without fee provided that the copies are not made or distributed for profit or commercial advantage AND that copies 1) bear this notice in full and 2) give the full citation on the first page. It is permissible to abstract these works so long as credit is given. To copy in all other cases or to republish or to post on a server or to redistribute to lists requires specific permission and payment of a fee. Contact Publisher@InformingScience.org to request redistribution permission. important insights for future design iterations.

Keywords: Online Learning Community, Social Software, Twitter, Design Science Research. 


\section{Introduction}

The U.S. Census Bureau shows approximately 20 million students enrolled in colleges and universities across the United States (U.S. Census Bureau, 2009). Of this population, 12 million, or $60 \%$, are between the ages of 18-24 and are considered traditional aged college students. Students within this age range are also referred to as millennial students by some researchers. Millennial students refer to those students having grown up with computers, the Internet, and video games (Oblinger \& Oblinger, 2005). While these students did not necessarily grow up with the prevalent online social networking sites we see today, they form a substantial percentage of online social networking users. Data from E-Marketer shows that $86 \%$ of millennial Internet users participate in some form of online social networking (Jenks, 2011). In May 2011, Ad Age identified 30\% of total Facebook users as being between the age of 18 and 24, and 32\% of all MySpace users were between the ages of 18 and 24 (Carmichael, 2011). A phenomenon we explore in more depth is the low penetration of millennials across microblogging sites, such as Twitter, the world's second largest social networking platform. Statistics across this technology indicate that only $13 \%$ of millennials use Twitter (Chappell, 2011). Adding a five-year upper margin, 18-29-year-olds comprise only $18 \%$ of Twitter's user base (Smith, 2011).

Nevertheless, institutions of higher learning see the potential social software has and are adapting institutional software to meet the needs of these millennial students. Consequently, transitions in course management system (CMS) software are occurring in new releases of Blackboard, Angel, Moodle and Sakai. In recent versions of these software platforms, instructors have the ability to incorporate blogging and collaborative writing to engage learners. Additionally, students have the ability to create more personalized profiles and communicate with classmates. Unfortunately, the costs of upgrading software and acquiring new software licenses can be steep and even the latest releases of these systems still lack features found across popular online social networking sites such as connection-making, microblogging and peer-to-peer file-sharing. Until these software components become ubiquitous across institutional software packages, we remain committed to using rigorous research to design, construct and evaluate social software components and their impact in the classroom.

\section{Background}

\section{Online Learning Community and Blogging}

When individuals enter college, they intrinsically become part of an academic community, where they are able to discover and share knowledge with their peers. First coined by Lave and Wenger (1991), academic communities are a type of "community of practice" (CoP) where individuals work together towards common goals, collaborating on common problems, sharing best practices, supporting one another, and sharing a common identity. Successful CoPs create sustained levels of engagement among individuals whereby knowledge sharing becomes an intrinsic function of the CoP (Adams \& Freeman, 2000).

Prior research has explored the bifurcation of online CoPs within higher education and found OLC software to be more closely aligned with traditional CoPs versus traditional CMS software (Thoms, Garrett, \& Ryan, 2009). More so than CMS software, an OLC empowers individuals to take ownership of their content while also making it easier to pursue social or scholastic ties with their peers.

OLC software is often facilitated by social media technologies such as blogging, discussion boards, collaborative writing, and peer-to-peer networking, making them a good fit for traditional college students, the majority of whom already participate in online social networking. This idea 
has been tested and validated across recent research to discover that various OLC components can positively influence learning and interaction and provide students with the ability to reflect on course material and expand in-class discussions into virtual spaces (Thoms, 2011). Research by Ractham and Firpo (2011) emphasizes how social software can alleviate the restrictions placed on student-to-student communication, eliminating the need for same-time, same-place environments. Studies by Brescia and Miller (2006) and Song and Yuen (2008) found numerous benefits to introducing blogging in the classroom, including enhanced student reflection, increased student engagement, portfolio building, and better synthesis across multiple activities. Additionally, Efimova (2009) measured the positive impact public blogs have in information sharing, motivation and discipline, and Kirkup (2010) identified how academic blogging can help students form an intellectual identity.

\section{Microblogging}

As identified above, blogging can successfully be used to foster learning and interaction. A natural extension to blogging, we argue, is microblogging. While only $13 \%$ of millennials use Twitter, microblogging sites are still largely popular (Chappell, 2011). Sites such as Twitter, Tumblr, and Jaiku provide individuals with innovative ways to communicate and provide numerous information-sharing features. Microblogs, as their name implies, restrict the size of the content users can disseminate during any one post (usually 140 characters), similar to a mobile text message. This forced brevity requires individuals to create succinct messages capable of conveying meaning in a relatively constrained space. As detailed in Li-Ping Tang and Austin (2009), microblogs enable individuals to know where the nodes of their community are, provide a sense of connectedness to and awareness of others, and have this sense even when members of the community are not within sight.

For our research study, we chose Twitter as our microblogging engine. Twitter, which celebrated its $6^{\text {th }}$ birthday on March 21, 2012, allows any user with a valid email address to create an account for free (Twitter, 2011). Once users have an account they are able to post content and/or view content from other Twitter account holders. Since its launch, Twitter has exploded into an information super-hub, where individuals share all types of real-time information from trivial status updates, to breaking news. Currently, the average number of Twitter posts, or tweets, per day is in the neighborhood of 140 million and, roughly, 1 billion tweets are made weekly. Additionally, the site boasts over 175 million accounts (Twitter, 2011).

One reason we chose Twitter was due to its immense popularity. Being as widespread as it is, a greater chance existed that students would already have accounts and/or would be familiar with the user interface. Additionally, Twitter has an advanced application programming interface (API), which allows third-party developers and researchers to easily integrate Twitter into customized applications. Furthermore, Twitter still dominates text-based microblogging, while other microblogs such as Jaiku and Tumblr have shifted towards more niche media formats such as images and/or videos. Twitter also provides a very user-friendly web interface and offers equally user-friendly mobile applications, which can be downloaded for free onto cell phones and smartphones and utilized anywhere wireless internet is available.

\section{Microblogging in Education}

As a powerful social technology, Twitter has been successfully implemented across many industries, including education. Twitter has been introduced and measured by educators looking to equip students with timely tools for quickly sharing and disseminating information with peers and faculty. Betta (2007) suggests that within an academic environment, microblogging can help build community by offering individuals the ability to continually inform others on what one is doing, discovering, or experiencing. This notion is supported by Grosseck and Holotesco (2008), 
who argue that the incorporation of microblogs models good pedagogy and can be responsive to a student's learning needs. Specifically, they argue that Twitter can change the classroom dynamic and offer a useful tool to share information, providing students with the freedom to discover new information, which can lead to higher levels of learning. Further research by Dunlap and Lowenthal (2009) found microblogging to be a powerful tool for enhancing social presence in addition to establishing informal, free-flowing, just-in-time communication between and among students and faculty. This research is supported in Ebner, Lienhardt, Rohs, and Meyer (2010), who conclude that microblogging can support learning beyond the traditional classroom through a constant flow of information between students and between students and teachers.

\section{Theoretical Model}

Since the onset of our research in 2006, theory has played a critical role for understanding how individuals use technology to foster learning and social interaction. Consequently, our research has led to a working model for OLCs in higher education. Illustrated in Fig-

ure 1 , this model is comprised of three distinct but integrated constructs: individuals, activities, and community. The model helps guide the design of information systems artifacts and identifies how individuals will utilize a wide range of technologies to share ideas and information with the larger community.

Our model incorporates theories of individual learning and classroom interaction (constructivism), peer-topeer interaction and community (social presence), and the various technology-based activities students perform to accomplish course objectives (activity theory).

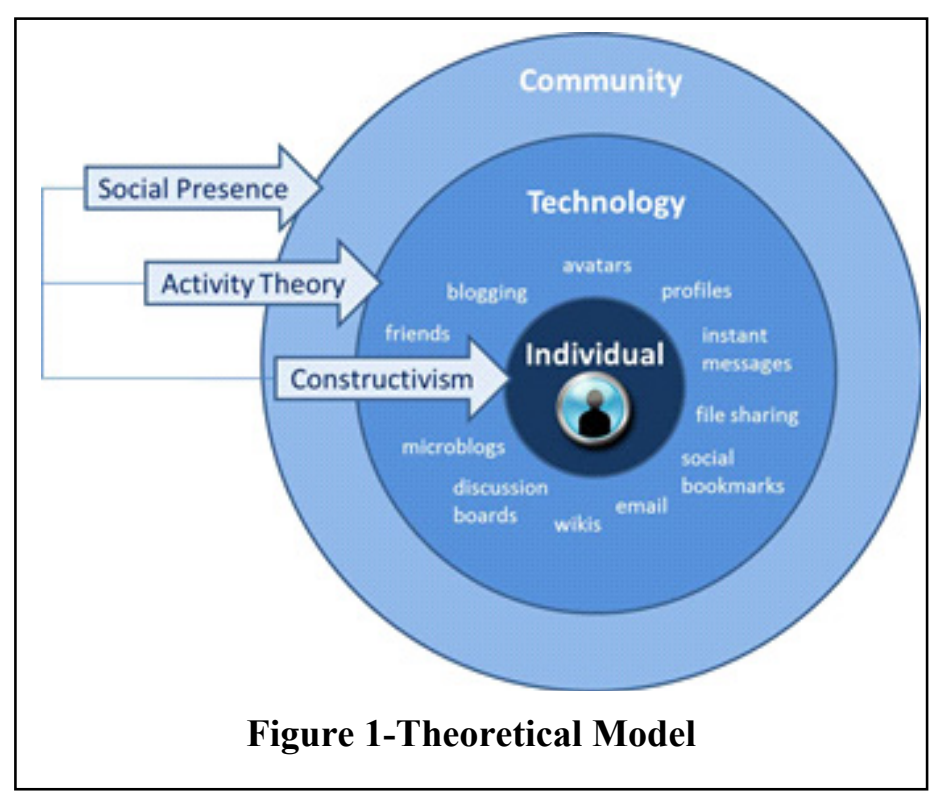

\section{Individual Level (Constructivism)}

At the nucleus of our model is the individual. Any learning environment must account for the unique needs of the individual, including how they participate within groups and utilize different technologies. Constructivism provides this lens. Largely linked to the work of Piaget (1952), constructivism attributes learning to the experiences and interactions a learner encounters within a specific context. Further research by Squires (1999) states that constructivism focuses on learner control, where learners make decisions that meet their individual needs based on their own cognitive state. Hagstrom and Wertsch (2004) add that a constructivist approach should encourage and reward a learner's unique and multidimensional characteristics across the learning process.

Prior research has traced the roots of an OLC to constructivism (Johnson, 2001; Palloff \& Pratt, 1999; Savery \& Duffy, 1996). As stated in Brown and Adler (2008), learning is socially constructed through conversations about that content and through grounded interactions, especially with others, around problems or actions. Further research asserts that interaction and dialogue are essential for productive learning (Cook, 2002; Nicol, Minty, \& Sinclair, 2003; Sorenson \& Takle, 2002). At the same time, an OLC should consider the individual learners' point of view (Soloway et al., 1996) and provide them with certain required levels of control (Squires, 1999). Most social 
software can support these requirements and motivate individuals through self-governing activities. Social software, as stated by Dalsgaard (2006), can be used to support a wide range of constructivist learning approaches by providing students with personal tools and better engage them through interaction.

In this specific research, we integrate blogging and microblogging software. Within each, students maintain complete control over the content they generate and moderate control over content created by their peers. Additionally, while students are provided with a dedicated learning space, they are not confined to this space alone and are encouraged to use the Internet and their social network to bring new information into the course. Asynchronous software can foster participation by providing students with the freedom to participate at their own discretion. And while students are expected to meet the minimum requirements for making class contributions, they are not limited to these minimum requirements and can choose to contribute and explore beyond.

\section{Community Level (Social Presence)}

From small seminars to large lecture halls, college classrooms are inherently social places, where individuals come together in the spirit of learning and disseminating knowledge. OLCs look to replicate these more traditional environments and provide individuals with mechanisms to discover and communicate with one another. In order for these online environments to thrive, a palpable sense of community must exist. Social Presence Theory, first coined by Short, Williams, and Christie (1976) focuses on how individuals perceive others in a community despite not being face-to-face. As today's online social networking technologies continue to evolve, so, too, has Social Presence Theory. Today, Social Presence Theory considers the degree of feeling, perception, and reaction to another intellectual entity within a computer mediated environment (Biocca, Harms, \& Burgoon, 2003; Tu \& McIsaac, 2002). As discussed in Garrison, Anderson, and Archer (1999), alternative methods for enhancing social presence must be explored to help substitute for the lack of visual cues individuals receive in face-to-face settings. Social Technologies work well in this regard and have successfully helped enhance social presence through peer feedback (Ma, 2008) and individual profiles and avatars (Vasileiou \& Paraskeva, 2010), both of which are implemented within our own OLC design.

In prior research, we discovered the positive effect blogging had on levels of social presence (Thoms et al., 2009). We enhanced this design further to include a dynamic feedback and ratings system (Thoms, 2011). In this research, we explore how microblogging can enhance social presence within an OLC. Taking full advantage of the Twitter API, our OLC design was enhanced to pull in new Twitter posts upon each page refresh. This means that content displayed across the site is lively, with new content shown in the OLC immediately after being generated. This steady influx of information gives the feel of an active community. Also helping to enhance social presence are the individual icons (a.k.a. avatars) that each student is required to upload upon logging into the OLC and creating a personalized profile. Additionally, attached to each tweet is a link to that student's OLC profile and their Twitter profile, where students can discover more about their classmates.

\section{Technological Level (Activity Theory)}

While it is important to understand learning and interaction at the individual-level and community-level, as design science researchers it is also important to consider those technologies that comprise the OLC. Activity Theory provides a great lens for viewing how individuals might use specific technologies to accomplish course goals. What makes Activity Theory compelling is that it not only considers how individuals use technologies, but embraces unconventional uses, so long as they help to accomplish proposed goals. This is supported in Issroff and Scanlon (2001), 
who assert that Activity Theory helps consider different factors surrounding a technology's use and how they contribute to desired outcomes.

From its origins, Activity Theory considers human actions to be directed at objects and mediated by artifacts (Bødker, 1989; Vygotsky, 1987). More simply put, an activity is the way individuals or groups move towards an end-goal with the purpose of attaining certain results or accomplishing certain objectives (Neto, Gomes, Castro, \& Sampaio, 2005). In educational environments, when instructors are able to choose activities from both online and face-to-face mediums, they are also able to select the activity that provides the best fit for any particular learning objective (Heckman \& Annabi, 2006; Mor, Tholander, \& Holmberg, 2005). Our research focuses on social technologies, because the introduction of such technologies into traditional CMS software has been slow.

Activity Theory can also be used for evaluating the effectiveness of those technologies. When studying motivations behind blogging, Nardi, Schiano, and Gumbrecht (2004) applied Activity Theory to help understand how bloggers' posts were influenced, to a large extent, by their relatively unknown Internet audience. Within this research, we integrate software, proven to have great success in helping individuals and organizations broadcast information, into OLC software to facilitate learning and social interaction. Microblogging is relatively unexplored within education; therefore, how students will utilize this emerging technology in achieving learning outcomes remains to be tested. Intrinsically, Twitter offers individuals a resource for sharing information when they want, where they want, and on whatever device they want. Students can also utilize the social aspects of the software to discover more about their classmates or search the Twitter website for external interests and connections.

\section{Artifact Construction}

Design Science Research (DSR) focuses on the way things ought to be in order to attain goals and researchers devise artifacts in order to achieve these goals (Simon, 1996). These IT artifacts are intended to solve identified organizational problems (Hevner, March, Park, \& Ram, 2004; Walls, Widmeyer, \& El Sawy, 1992). An artifact, as detailed by Benbasat and Zmud (2003), is any hardware/software design encapsulating structures, routines, norms, and values implicit in the rich contexts within which the artifact is embedded. In other words, the artifacts will be those technologies students use to accomplish course objectives. With the success of our OLC in recent design iterations, particularly with the blogging component, we look to further enhance design to incorporate a microblogging component and measure its impact on learning, social interaction and community. More specifically, we integrate the microblogging component into the latest version of Elgg.

\section{Software Platform}

It is estimated that the adoption of CMS software among today's colleges and universities is above $96 \%$ (MDR, 2003). CMS software provides powerful platforms for the facilitation and management of academic course work allowing instructors to receive student submitted assignments, enter/review grades, create group discussions, and communicate with students. However, as discussed earlier, CMS platforms are only beginning to introduce social software components and they fall short in replicating the social networking experiences of widespread online systems such as Facebook and Twitter.

The CMS platform used at our university is Angel, which is owned and supported by Blackboard Inc. Angel v7.4 contains a blogging engine with significant flaws. Illustrated in Figure 2, the blog space lacks even basic social features such as avatars and links to individual profiles. The component also lacks basic information sharing capabilities such as the ability to embed images or 
video. For these reasons, in addition to the fact that Angel is a closed source environment, which is unable to be enhanced, we decided to choose Elgg as the OLC platform.

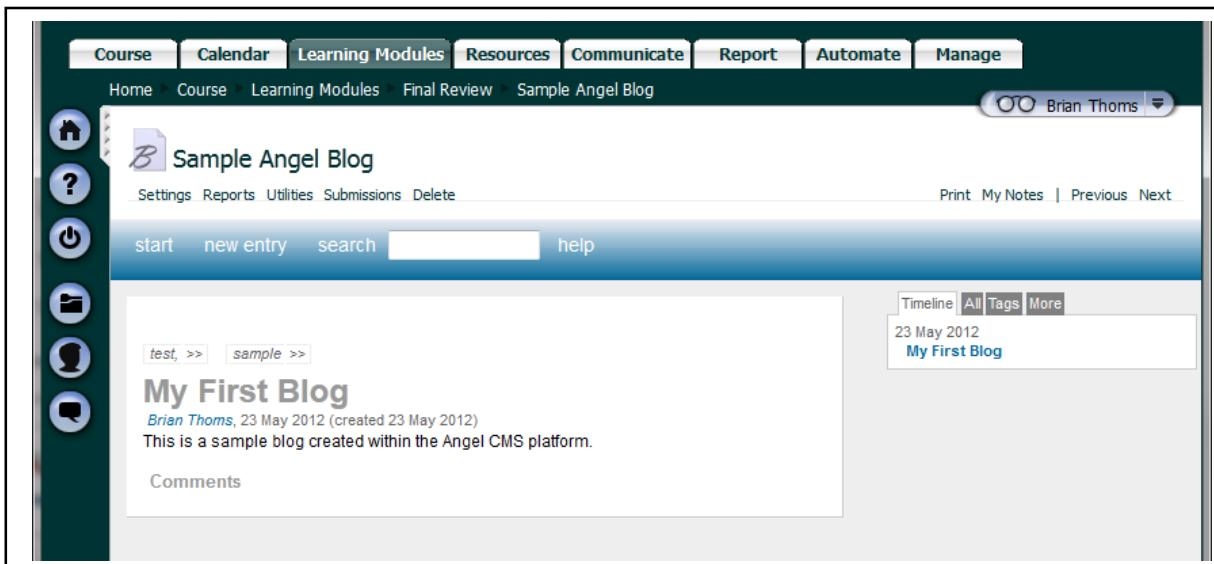

Figure 2-Angel Blog Component

\section{Elgg: Online Learning Environment}

Having a software platform that is adaptable to the needs of instructors and students is critical. Our initial review of social software began in the spring of 2006, when we evaluated a variety of proprietary and open source social networking software. We compared these technologies based on cost, usability, customizability, extensibility, and the range of features each provided. Even in its beta release in 2006, Elgg stood out as the platform of choice for its range of social features and easy-to-use interface. Additionally, as open source software, Elgg maintained a close-knit core of software developers. As one would expect, Elgg has progressed across all features since 2006. Today, Elgg v1.7.6 comes bundled with profile building, blogging, file sharing, the ability to create unlimited sub-communities, and peer-to-peer networking capabilities. Additionally, Elgg provides for the ability to restrict access to data across a number of levels, including individuallevel, group-level, user-level, and custom levels of restriction.

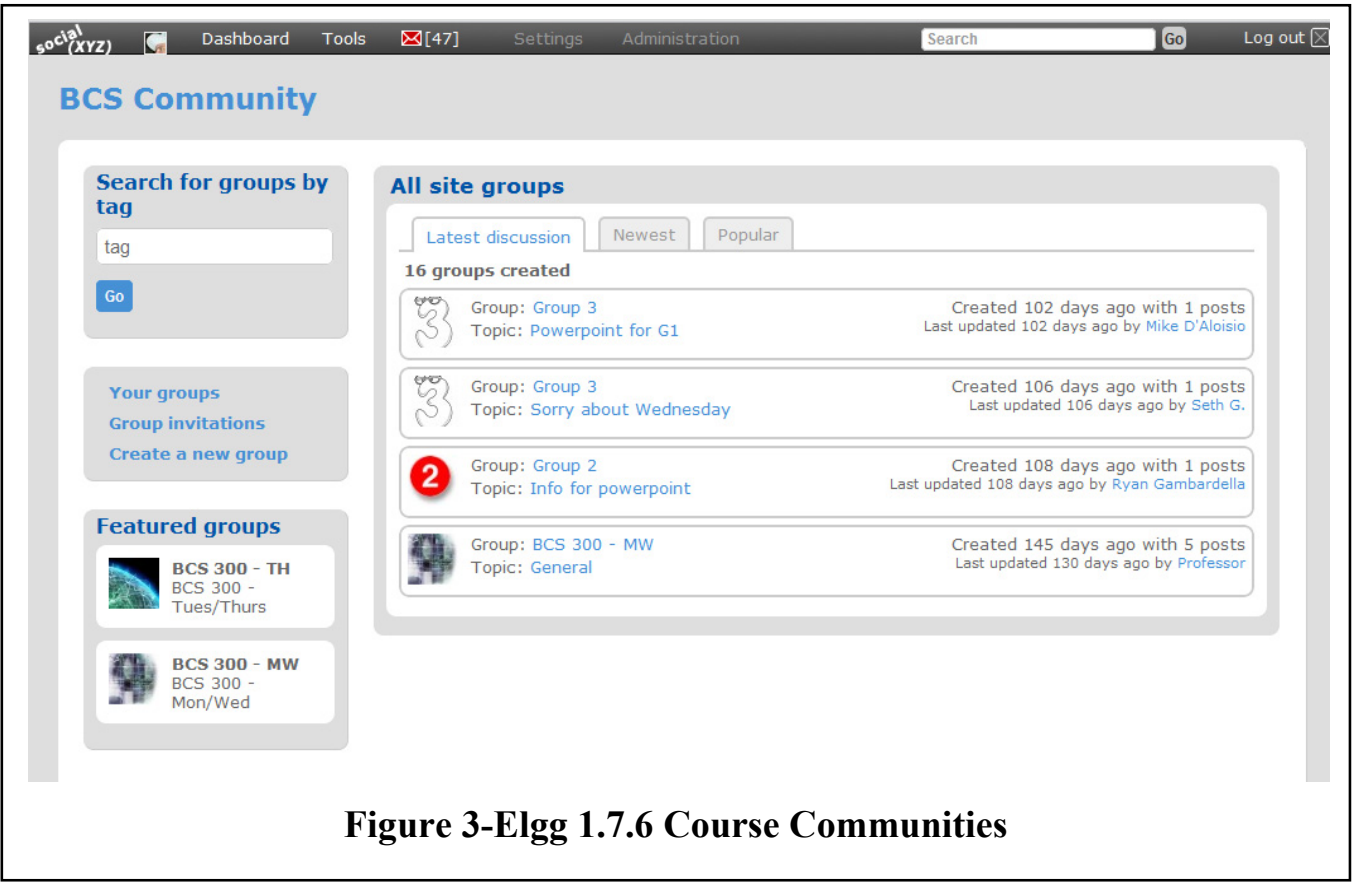


To date, research has shown Elgg to function particularly well in higher education and has helped compliment aspects where CMS systems fall short. Illustrated in Figure 3 is the ability for any user to create a sub-community, known as 'groups'. This feature highlights Elgg's capability for providing instructors the ability to create as many groups as they have classes. Additionally, students can create groups for classroom-related activities, where each group has dedicated resources designated to assigned group members.

\section{Twitter Integration}

Before constructing our microblogging module, we investigated available third-party plugins for Elgg. Unfortunately, we found that the available plugins were very limited and none had a mechanism to filter tweets based on some predefined content. Existing modules also offered no way to collectively showcase tweets for specific Elgg groups (i.e., by specific course). Therefore, we decided to construct our own module that extracted content directed at the course instructor and displayed each tweet in chronological order across the OLC dashboard.

Integrating Twitter with Elgg was straightforward due to the adoption of Internet standards and the openness of both systems. While closed source, Twitter does provide an application programming interface (API) for developers. The API allows programmers to build customized software which can pull information directly from the live Twitter data feed. The data is returned in XML format and can easily be customized to any application interface. Consequently, applications can make specific search requests to query the Twitter live feed for specific tweets. This feature allows developers to construct queries to extract tweets containing specific words, 'BCS300', or to and from specific users, 'BCS300_Instructor'. Furthermore, these search parameters can be combined to generate even more complex queries. Illustrated in Figure 4, students participating in course assignments would utilize Twitter to tweet using the @BCS300_Instructor syntax. This syntax,@TwitterUser, is more commonly referred to as a "Shout-At". Consequently, in order for an individual to shout at members of the course and have those tweets feed into the Elgg system, they would need to prepend each tweet with @BCS300_Instructor for those posts to reach the OLC.

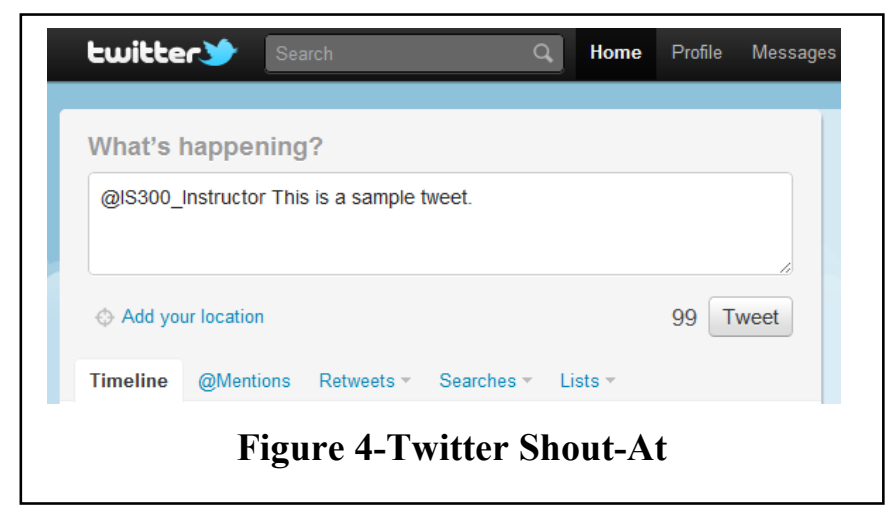

\section{Microblog / Blog Integration}

As application developers for Elgg, the API provides the capability of generating custom Twitter modules. An initial step towards integrating Twitter with the Elgg blogging engine involved enhancing the Elgg dashboard (or homepage) to showcase recent tweets. Illustrated in Figure 5 is a portion of the OLC dashboard and the view a user would see upon logging into the system. In the left column, immediately underneath Group memberships, the user would see a complete list of recent community tweets. This module presents users with the 1) tweet, 2) OLC user name and icon with link to the user profile, 3) Twitter account name with a link to their external Twitter profile and 4) an additional link, "Blog It," which allows individuals to create a new blog post based on any specific tweet. 


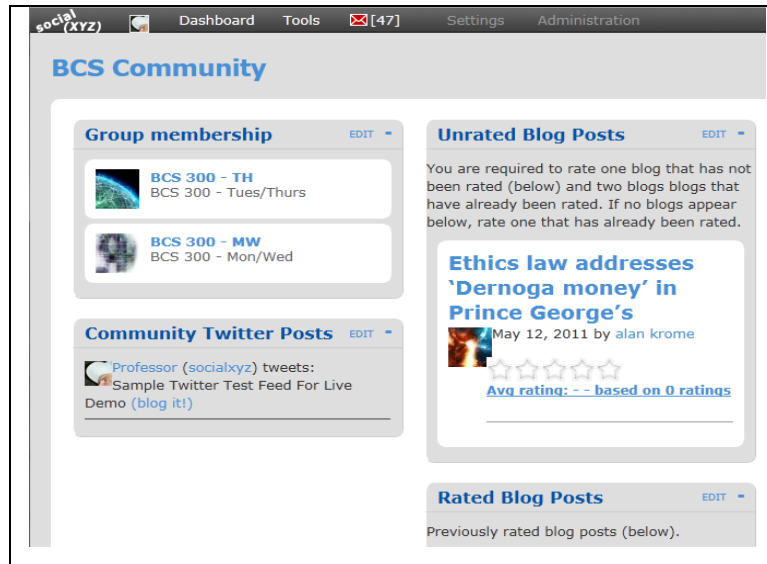

Figure 5-OLC Dashboard

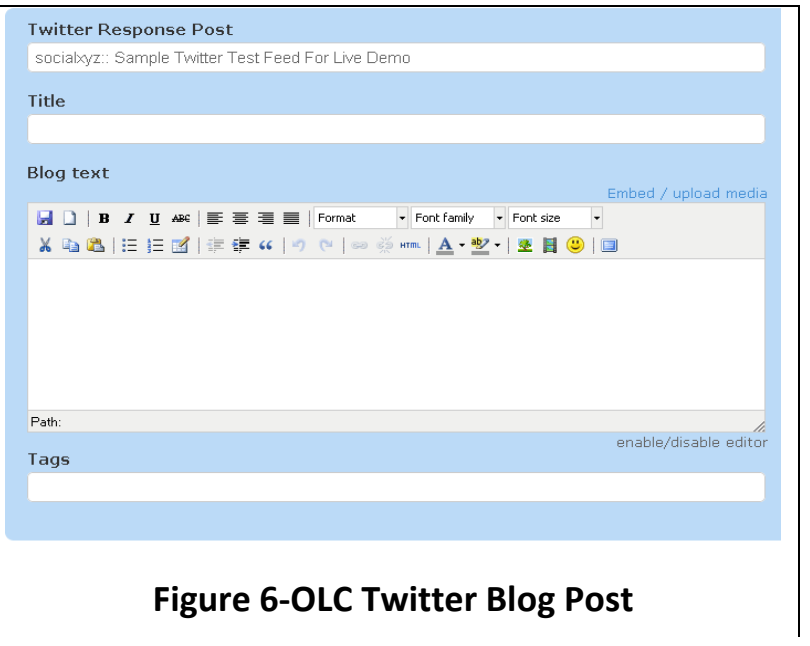

Figure 6-OLC Twitter Blog Post

Figure 6 provides a snapshot of the Elgg blog entry screen. In this particular screenshot, a user has chosen to create a new blog post based on a recent tweet. To accommodate this feature, a new database table was created to store tweets linked to specific blog posts. The table stored the original Twitter post, author and the date it was posted. Additionally, the tweet would then be associated with that specific post and would be viewable from within the post.

\section{Research Design}

To help validate our OLC design, we targeted specific information systems courses. Our experiment can be categorized as a one-group quasi-field experiment since random assignment was not performed. Similar to the characteristics of a field experiment, we measure the effects of our intervention on an existing population of college students where pre-existing baselines exist for which to compare results.

\section{Research Questions}

The semester-long experiment looked to explore the following high-level research questions:

- What are students' initial perceptions of using Twitter to support course learning, interaction, and community?

- How will the introduction of Twitter affect students' perceptions of using Twitter to support course learning, interaction, and community?

- What impact will a microblogging have on learning, interaction, and community?

\section{Research Methodology}

To explore these questions, the OLC was implemented across multiple sections of BCS300, a capstone course in information systems required for all information systems majors. As detailed in the course catalog, "BCS300 examines the various levels and types of software and information systems required by an organization to integrate these functions." Each section was setup identically and each contained 25 students. The blogging and microblogging components were incorporated into the course learning objectives as technology assignments and required for $20 \%$ of the course grade. Each technology assignment was broken down into three parts:

- Part 1 required students to use Twitter to retrieve relevant course content.

- Part 2 required students to blog about either 1) course content for that week or 2) a Twitter post made by a fellow classmate. 
- Part 3 required that students provide feedback on content generated across the site.

In all, seven technology assignments were assigned. As one example, Part 1 of Technology Assignment 7 required students to tweet about one article they found online that raises ethical considerations and relates to a specific type of information system discussed over the course of the term. Students were instructed to provide a one-line summary and a link to the article. Part 2 was to provide a 5-8 sentence blog response to a classmate's tweet. And Part 3 required that they provide additional feedback across the course of the week using blog ratings or blog comments.

\section{Results}

To measure the impact of our intervention we conducted and analyzed pretest and posttest surveys. Pretest survey questionnaires were distributed to each section of BCS300 resulting in 40 usable responses, or an $80 \%$ response rate. Posttest survey questionnaires were distributed to both sections resulting in 35 usable surveys, or a $70 \%$ response rate. We also looked at studentgenerated blog and microblog content and compared them with student-grades. Data for this analysis was collected from all course participants.

\section{User Population (Pretest)}

Demographic data collected indicated that $97 \%$ of students were traditional college students and were between the ages of 20 and 25 , with only $3 \%$ over the age of 40 . The ratio of male to female participants was $71 \%$ male and $29 \%$ female.

\section{Technology Experience (Pretest)}

Pretest data looked at student experiences and perceptions of online learning using blogging and microblogging. Illustrated in Figure 7, responses showed that $98 \%$ of students had experience with social networking software, with $80 \%$ indicating high levels of experience. Surprisingly, while $67 \%$ had some experience blogging,

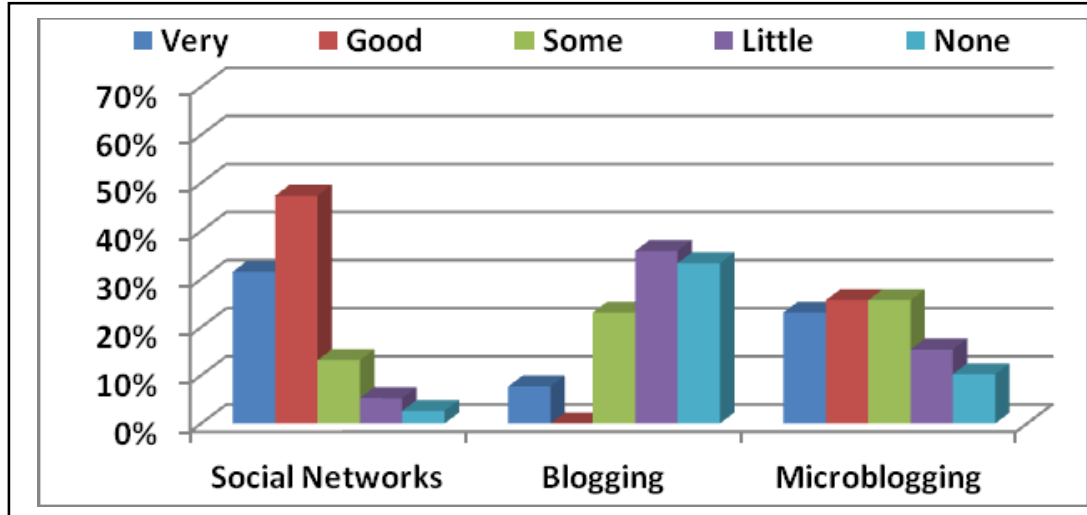

Figure 7-Technology Experience only $8 \%$ had high levels of experience. More students expressed experience with microblogs $(90 \%)$ and $49 \%$ indicated high levels of experience. These abnormally high levels of microblogging experience for this demographic can be attributed to Facebook status updates, which were included as one type of microblog. To better understand these numbers, additional data collected looked at when users made their first 'real' tweet. From this data, we estimated that only 14 students $(28 \%)$ tweeted from previously created Twitter accounts, while 35 students $(72 \%)$ made their first tweet specifically for class credit.

\section{Perceptions on Learning (Pretest)}

Illustrated in Figure 8, pretest questions looked at initial student perceptions of interaction and community on learning. It was encouraging to identify that the majority of students agreed that 
interaction (85\%), collaboration (62\%), information exchange (80\%) and community $(80 \%)$ would be important aspects of the course with little to no disagreement across these survey items.

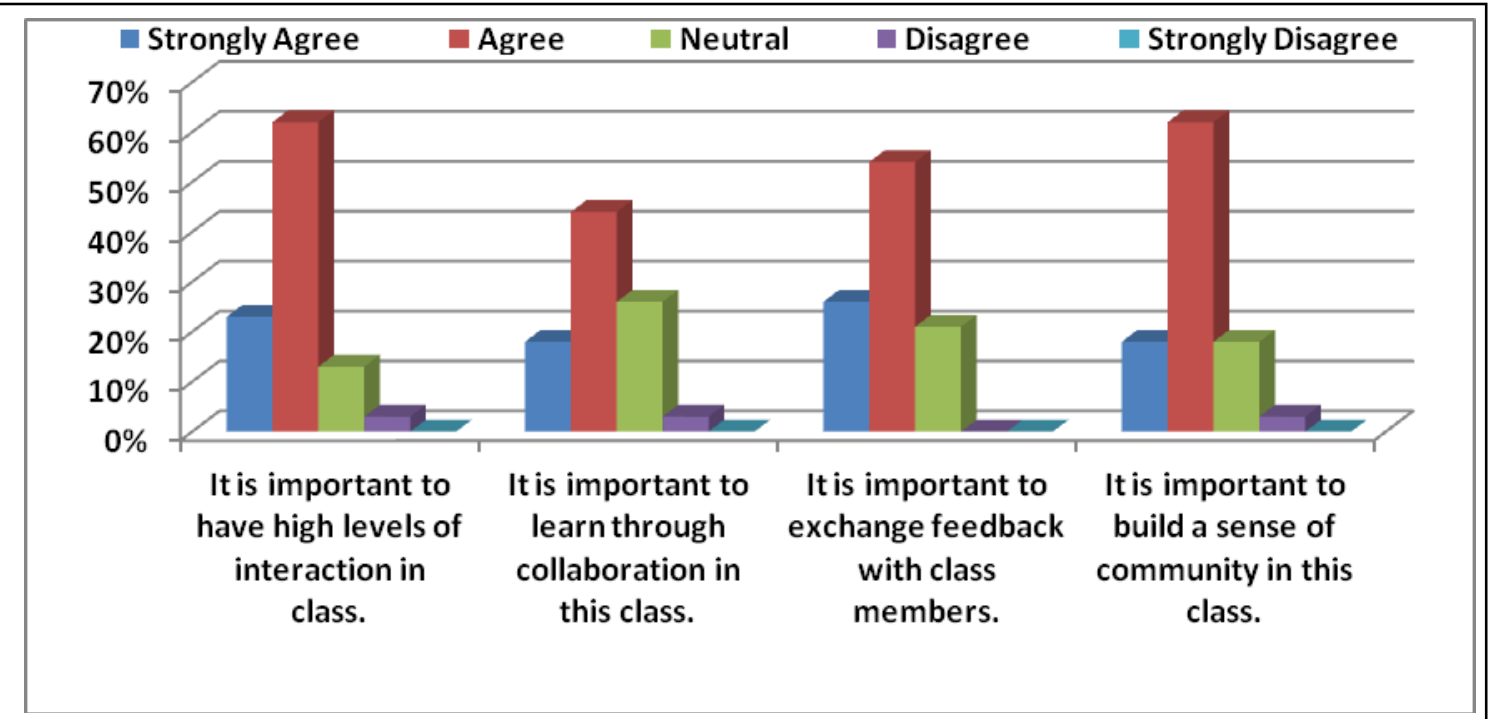

Figure 8-Student Perceptions on Social Interaction, Community and Learning

\section{OLC Usage, Content Creation and Grades}

The software was utilized during the spring 2011 semester, from January 24, 2011 to May 12, 2011. Excluding the course instructor, the online environment averaged 50 active users (defined as users who logged into the system at least once during the semester). The site averaged 27 visits a day and 2,890 total visits, averaging 9.5 pages a visit.

During this timeframe, and detailed in Table 1, 285 blog posts were created, 78 of which linked to one or more of the 439 tweets made. On average, 9 tweets and 6 blog posts per student were created. Users also generated 671 blog ratings and 342 blog comments. Survey data indicated that $94 \%$ of respondents used the OLC daily or weekly with 3\% using it monthly. Additionally, $74 \%$ indicated blogging daily or weekly and $26 \%$ bi-weekly or monthly. No student indicated that they did not post to the blog.

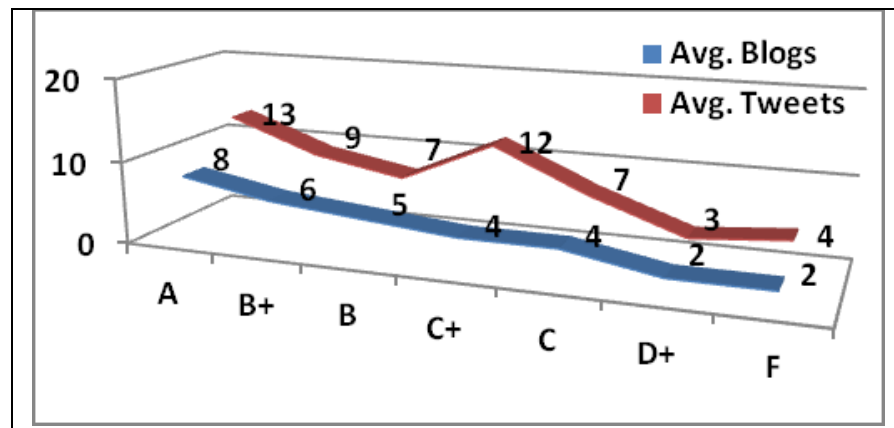

\begin{tabular}{|l|l|l|}
\hline \multicolumn{3}{|c|}{ Table 1-OLC Statistics } \\
\hline & COUNT & AVERAGE \\
\hline Students & 50 & $80(\mathrm{~B})$ \\
\hline Page Views & 27,395 & 9.5 \\
\hline Blog Posts & 285 & 6 \\
\hline Tweets & 439 & 9 \\
\hline
\end{tabular}

Figure 9-Grade Distribution vs. Content

Figure 9 illustrates the grade distributions versus the number of tweets and blog posts made by each student. Students receiving grades of A, B+ and B met both the average requirements for posting blogs, which was five, and microblogs, which was seven. Students receiving grades C+ 
and $\mathrm{C}$ met the microblog requirements but failed to meet the blogging requirement. For assignments where microblogging and blogging were both assigned, each accounted for $50 \%$ of the assignment grade. Finally, students not meeting the microblog or blog requirements received grades of $\mathrm{D}+$ or $\mathrm{F}$.

\section{Perceptions on Twitter, Learning, Interaction and Community (Pretest / Posttest)}

As detailed in Figure 10, we utilized aggregate pretest and posttest survey results for comparison purposes and compared students' initial perceptions of Twitter's capability to support learning with results after 109 days. Across this construct, $43 \%$ of students showed general optimism, while $49 \%$, close to half, showed skepticism that Twitter could positively impact learning. After using the software, while $43 \%$ still agreed that Twitter helped to support learning, there was a shift in neutral responses from $49 \%$ to $23 \%$ and $35 \%$ of individuals indicated that Twitter did not support learning.

This downward shift was also present on perceptions of Twitter to support interaction. Pretest data indicated that $77 \%$ of students felt that Twitter would support interaction, with only $8 \%$ disagreeing with this statement. Posttest data identified that only $25 \%$ of respondents felt that Twitter actually increased interaction with $29 \%$ disagreeing with this statement.

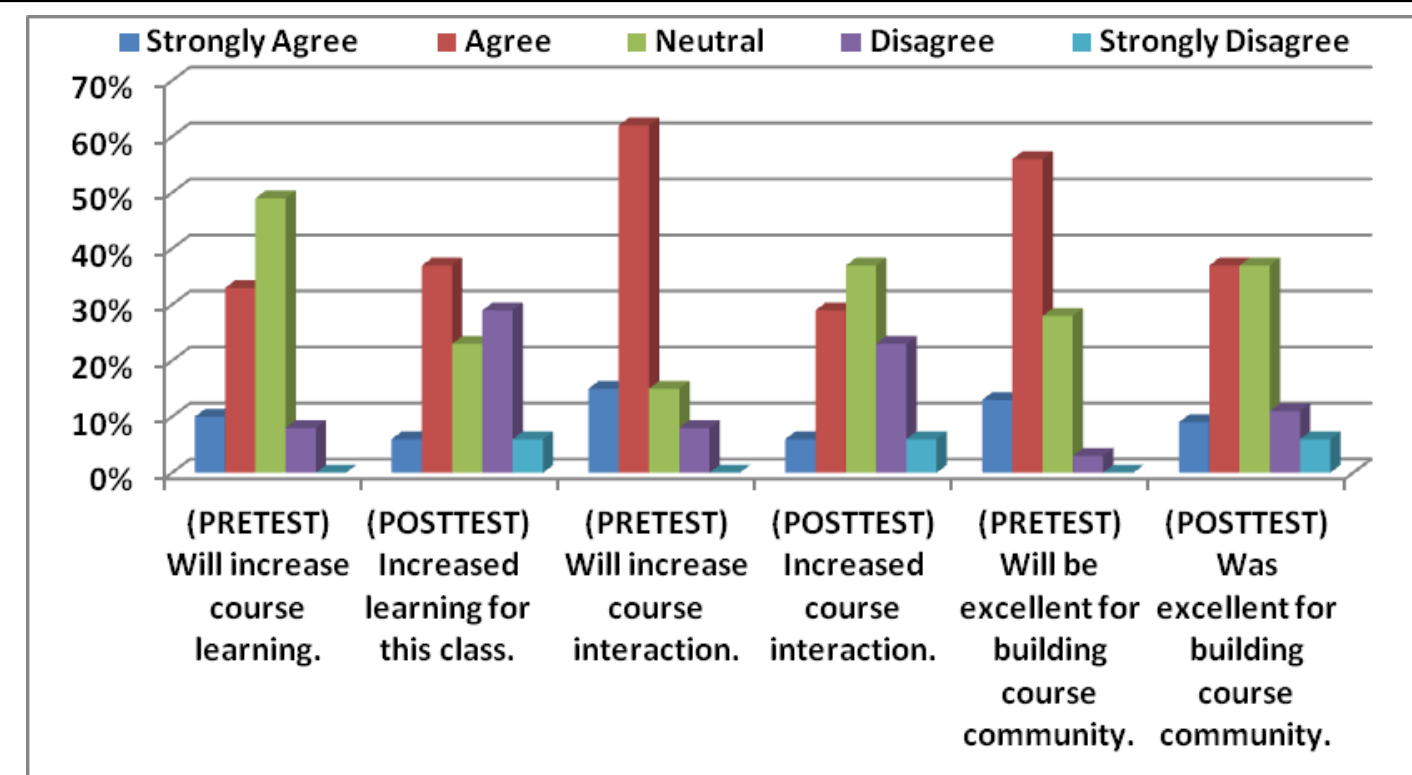

Figure 10-Students Perceptions on Twitter and Learning, Interaction and Community

Survey results for community-building yielded similar trends. Pretest data identified that $69 \%$ of respondents agreed that Twitter would increase levels of community, while posttest data resulted in only $45 \%$ agreement across this construct. And disagreement across these levels shifted from $3 \%$ in the pretest to $17 \%$ in the posttest.

\section{Knowledge Building (Posttest)}

Our posttest also looked at overall user experience using Twitter in addition to Twitter's ability to facilitate information sharing. Overall, students had a very positive experience using Twitter and $74 \%$ agreed or strongly agreed with this statement. There was also general agreement $(65 \%)$ that Twitter helped students to bring new information into the course. Additionally, most students 
agreed that Twitter helped them to explore information outside the course textbook. A complete breakdown of responses is found in Figure 11.

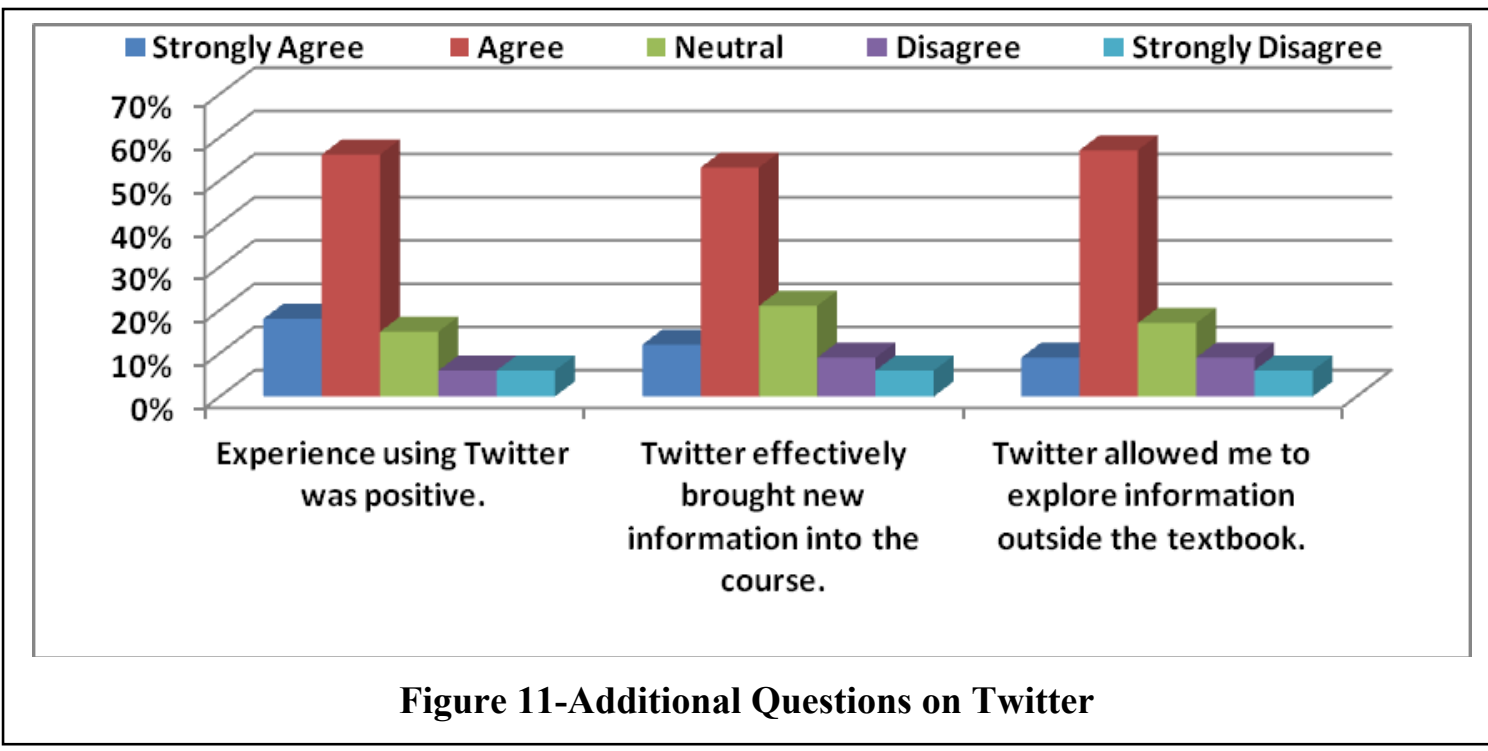

\section{Discussion}

Understanding the role higher education plays in society can be difficult. At one level, education is concerned with preparing students for their roles as problem solvers in today's knowledge society. Increasingly, these roles are becoming more collaborative, requiring workers to synthesize information across multiple domains and share that information among the collective group. It is our belief that in addition to introducing students to fundamental concepts in information systems, higher education should also introduce students to and prepare students for using powerful tools for information retrieval and collaboration. In this research we integrated Twitter into upperdivision courses on information systems and measured its effects on learning and interaction.

\section{Twitter on Learning}

At the center of an OLC and what distinguishes it from other social networking software is its focus on learning. While individuals participate and socialize across this learning space, students aim to acquire and construct new knowledge in the process. Therefore the goal of embedding Twitter into the course OLC was to foster student's understanding of a particular subject matter.

Prior research discovered numerous benefits to blogging in classroom settings (Thoms, 2011; Thoms et al., 2009). Blogging within our own OLC was found to be largely successful in this regard, achieving levels of agreement as high as $77 \%$. As a tool designed to enhance the blogging experience, we were surprised to discover that Twitter received only $43 \%$ agreement across this construct. This was particularly surprising given the fact that the majority of students agreed that it helped them bring new information into the course (65\%) and explore new information not found in the course textbook (66\%).

In this respect, Twitter can be seen largely as a broadcast technology. As such, Twitter allowed students to share all types of information with the class and view what other members of the class wished to share. And to do so, students frequently searched relevant news outlets for articles pertaining to information systems and used Twitter to bring this information back into the OLC. Consequently, students produced very interesting content. In one post a student tweeted, "If a teenager sends more than 110 text messages in a day they are considered a hyper-texter." Another 
posted, "Facebook is worth an estimated $\$ 65$ billion. Zuckerberg is the only billionaire on Forbes 500 younger than 30 yrs old." Another stated, "Facebook and Twitter are being used to help fight crime. Information gathered from these sites can be used as evidence." We also uncovered that 147 tweets, or $34 \%$, contained links to external resources. This was largely encouraged, but not necessarily required for course credit.

While the content generated across the semester was informative, results showed weak relationships between tweeting and learning and tweeting and social interaction. As we analyze the content generated, we begin to assert that broadcast technologies, such as Twitter, are not the best at facilitating understanding or showcasing comprehension. This happens to be true for a lot of classroom technologies that look to engage students inside or outside the classroom. Examples of other technologies, such as classroom clickers or peer ratings, are designed to engage or motivate students, rather than directly contribute to the learning outcomes of a particular subject matter. Therefore we make the claim that Twitter can be extremely effective in engaging students. In this experiment, Twitter helped students bring new information into the course community where conversations can develop further. Of the 285 blog posts, 78 blog posts, or $27 \%$, were created from an initial tweet. This indicates that students found something interesting in that initial post and were able to reflect more deeply upon that content with deeper meaning in a blog post.

\section{Twitter on Interaction and Community}

On the outer stratum of our theoretical model, which separates OLCs from traditional CMS software is the focus on social interaction. We introduced Twitter into our OLC as a mechanism for asynchronous course interaction and community building. Twitter is the second largest online social networking platform, used globally, and fosters millions of connections and generates hundreds of millions of tweets each week. We discovered that, while overall levels of agreement on how effective the OLC was at building interaction and community were high $(65 \%$ and $82 \%$ respectively), these levels were much lower for Twitter (35\% and $46 \%$ respectively).

To understand this further, we examined student tweets; specifically those posts that looked to engage the larger course community. During initial assignments, some students tried to use Twitter to interact with classmates and posted questions to the larger community. One student tweeted, "Does anyone think school will begin using Twitter for weather closing contacts before or after it hits critical mass?" Another tweeted, "Is there a way to view all of the unrated or rated blog posts for the class on the dashboard or is it random?" Unfortunately, the Twitter Feed was one-way and while information fed into the OLC, the OLC could not be used to respond directly to tweets. Thus, students were required to use some other medium for follow-up communication such as blogs, comments or email. Consequently, most students chose simply to rebroadcast information they found across the Internet, rarely trying to engage the greater community.

It would be incorrect to suggest that Twitter cannot support the levels of course interaction and community we initially sought. Rather, we see the failure stemming from our OLC design; specifically in linking microblogs with traditional blogs. In hindsight, the only real interaction that took place through Twitter occurred when students performed their initial Shout-At. Shout-Ats were required to bring tweets into the course OLC and all Shout-Ats were directed at BCS300_Instructor. Thus, while we observed that Twitter was successful in bringing new information into the course and exploring new information, the software only allowed individuals to share information with the class and offered minimal interaction beyond that.

Reflecting back on the objective of Design Science Research, it is critical that we address why our proposed design did not bring about the desired effects on learning, interaction, and community. Since our results showed that student experience using Twitter was positive (72\%), we believe we are on the right track by introducing microblogging into the classroom. A key challenge 
is now finding the correct blend of technologies that can exploit Twitter's full potential. Our results indicate that the problem centers on how tweets are handled once they enter the OLC. Since only 119 out of 439 tweets (27\%) generated any further discussion (Table 1), blogs are clearly not the correct method for expanding upon the ideas originated within the microblog. In subsequent design iterations we plan to integrate the microblog, either Twitter or an Elgg-based version, with a discussion board, where students can continue the conversation within the confines of the OLC. We also look to integrate an existing platform for rating blog posts to provide students with the ability to rate tweets, which may add an added layer of interaction.

\section{The Overall Twitter Experience}

An interesting discovery made was the larger percentage of students using Twitter versus the overall demographic trends. As touched upon in the Introduction, only $13 \%$ of millennial students use Twitter, yet our results identified that almost $30 \%$ were previously using Twitter to share information online (Figure 7). While we do not analyze these results in detail, we see that overall trends across this medium are shifting. And, as this population becomes more versed in microblogging, the potential for greater integration across areas of higher education will increase. Consequently, it is important to embrace the technologies in their relative infancy and explore potential areas for success. It is our conviction that the introduction of social software into the classroom continues to provide numerous tangible and intangible benefits not measured completely in this study. Today's business environments rely on numerous technologies, including social media. Thus, introducing students, particularly information systems students, to these systems may go a long way in better preparing them for industry.

Additionally, as researchers in Design Science Research, an important goal involves discovering new or existing technologies that can facilitate course learning objectives. A primary construct of Activity Theory considers how IT artifacts can be used in different ways to achieve specific outcomes. Twitter, as is the case with many other social technologies such as blogs and wikis, provides individuals with the freedom to participate whenever, wherever and, thanks to the Twitter API, on whatever device they feel most comfortable sharing information. While we feel we could have provided an enhanced OLC platform with Twitter integration, we see a more powerful role for Twitter in future design iterations. Additionally, an underlying theme of our research is to continue to push CMS platforms to include more dynamic and student-centric software that incorporates existing social technologies. And on the opposite side of the fence, instructors should be challenging students across a broader range of digital media that will provide students with critical new information retrieval and problem solving skills.

\section{Limitations}

While we were able to gain a good understanding of student perceptions of Twitter used in an OLC, we understand that limitations exist. For confidentiality reasons, we were unable to link posttest data with pretest data and OLC content. This meant that, while we were able to link activities to grades, we were not able to triangulate between perceived learning, system usage, and student grades. Similarly, our research does not measure actual learning but learning as perceived by the individual. We are still looking into ways around this problem to get a more accurate depiction of student perceptions and actual learning outcomes.

Some technical limitations existed as well. During out study we discovered a number of flaws with the Twitter feed. One problem was that, while posts made via Twitter's website are realtime, retrieving posts from the Twitter feed is not and, in some cases, can be delayed up to one hour. Additionally, for some unknown reason, we found that tweets from some users never reached the data feed. Lastly, unless a tweet is re-tweeted (resent), the Twitter feed will only keep one week's worth of tweets. 


\section{Conclusion}

In this research we evaluate student perceptions on microblogging across multiple information systems courses. More specifically, we design and evaluate the integration of Twitter, a microb$\log$, with Elgg, an online social learning platform. Students utilized Twitter to bring new information into the course community where they could continue the conversation in a closed learning environment. The system was incorporated into two upper-division undergraduate courses on information systems where we measured its impact on course learning, social interaction, and community. While initial findings across learning, interaction, and community survey constructs indicated decreased levels of agreement from pretest to posttest, user experience with Twitter was largely positive and there was general agreement that Twitter can be used as a powerful tool in exploring and bringing new information into the course.

As we continue to build and extend our OLC, we remain positive that future design modifications and better alignment with course learning objectives will foster higher levels of course learning, interaction and community within educational environments.

\section{References}

Adams, E., \& Freeman, C. (2000). Communities of practice: Bridging technology and knowledge assessment. Journal of Knowledge Management, 4, 38-44.

Benbasat, I., \& Zmud, R. W. (2003, June). The IS identity crisis. MIS Quarterly, 27(2), 183-195.

Betta, C. (2007). Social networking and academic life. Delft University of Technology.

Biocca, F., Harms, C., \& Burgoon, J. (2003). Toward a more robust theory and measure of social presence: Review and suggested criteria. Presence: Teleoperators \& Virtual Environments, 12(5), 456-480.

Bødker, S. (1989). A human activity approach to user interfaces. Human-Computer Interaction, 4, 171-195.

Brescia, W., \& Miller, M. (2006). What's it worth? The perceived benefits of instructional blogging. Electronic Journal for the Integration of Technology in Education, 5, 44-52.

Brown, J., \& Adler, R. (2008). Minds on fire: Open education, the long tail, and learning 2.0. Educause, $\mathrm{Jan} / \mathrm{Feb}$.

Carmichael, M. (2011, May 16). The demographics of social media. Retrieved July 03, 2011, from http://adage.com/article/adagestat/demographics-facebook-linkedin-myspace-twitter/227569/

Chappell, B. (2011, April 06). 2011 social network analysis report-Geographic-Demographic and traffic data revealed. Retrieved July 03, 2011, from Ignite Social Media: http://www.ignitesocialmedia.com/social-media-stats/2011-social-network-analysis-report/\#Twitter

Cook, J. (2002). The role of dialogue in computer-based learning and observing learning: An evolutionary approach to theory. Journal of Interactive Media in Education.

Dalsgaard, C. (2006). Social software: E-Learning beyond learning management systems. European Journal of Open, Distance and E-Learning.

Dunlap, J., \& Lowenthal, P. (2009). Tweeting the night away: Using Twitter to enhance social presence. Journal of Information Systems Education, 20(2), 129-136.

Ebner, M., Lienhardt, C., Rohs, M., \& Meyer, I. (2010). Microblogs in higher education - A chance to facilitate informal and process-oriented learning? Computers \& Education, 55(1), 92-100.

Efimova, L. (2009). Weblog as a personal thinking space. Proceedings of the 20th ACM conference on Hypertext and Hypermedia. ACM.

Garrison, R., Anderson, T., \& Archer, W. (1999). Critical inquiry in a text-based environment: Computer conferencing in higher education. The Internet and Higher Education, 2(3), 87-105. 
Grosseck, G., \& Holotesco, C. (2008). Can we use Twitter for educational activities? The 4th International Scientific Conference eLSE: eLearning and Software for Education. Bucharest.

Hagstrom, F., \& Wertsch, J. (2004). The social construction of identity: The clinical challenge. Topics in Language Disorders, 24(3), 162-173.

Heckman, R., \& Annabi, H. (2006). Cultivating voluntary online learning communities in blended environments. Journal of Asynchronous Learning Networks, 10(4).

Hevner, A., March, S. T., Park, J., \& Ram, S. (2004, March). Design science in information systems research. MIS Quarterly, 28(1), 75-105.

Issroff, K., \& Scanlon, E. (2001). Case studies revisited - What can Activity Theory offer? First EuroCSCL Conference, (p. 2001). Maastricht.

Jenks, J. (2011, May). The digital world of millennials. eMarketer.

Johnson, C. (2001). A survey of current research on online communities of practice. Internet and Higher Education, 4(1), 45-60.

Kirkup, G. (2010). Academic blogging: Academic practice and academic identity. London Review of Education, 8(1).

Lave, J., \& Wenger, E. (1991). Situated learning: Legitimate peripheral participation. Cambridge: Cambridge University Press.

Li-Ping Tang, T., \& Austin, M. (2009). Students' perceptions of teaching technologies, application of technologies, and academic performance. Computers \& Education, 53, 1241-1255.

Ma, A. (2008). Computer supported collaborative learning and social creativity: A case study of fashion design. Journal of Information, Information Technology, and Organizations, 3, 17-39. Retrieved from http://jiito.org/articles/JIITOv3p017-039Ma453.pdf

MDR. (2003). Colleges increase use of course management systems. Educational Marketer, 34(8).

Mor, Y., Tholander, J., \& Holmberg, J. (2005). Designing for constructionist web-based knowledge building. Conference on Computer Support For Collaborative Learning: Learning 2005: the Next 10 Years!. pp. 450-459. Taipei, Taiwan: International Society of the Learning Sciences.

Nardi, B., Schiano, D., \& Gumbrecht, M. (2004). Blogging as social activity, or, would you let 900 million people read your diary? 2004 ACM Conference on Computer Supported Cooperative Work (pp. 222231). Chicago, Illinois: ACM.

Neto, G., Gomes, A., Castro, J., \& Sampaio, S. (2005). Integrating activity theory and organizational modeling for context of use analysis. Latin American Conference on Human-Computer Interaction. 124. Cuernavaca, Mexico: ACM.

Nicol, D., Minty, I., \& Sinclair, C. (2003). The social dimensions of online learning. Innovations in Education and Teaching International, 40(3), 270-280.

Oblinger, D., \& Oblinger, J. (2005, June 23). Is it age or IT: First steps toward understanding the net generation. In D. Oblinger, \& J. Oblinger (Eds.), Educating the net generation. Retrieved from Educause.

Palloff, R., \& Pratt, K. (1999). Building learning communities in cyberspace: Effective strategies for the online classroom. San Francisco,CA: Jossey-Bass.

Piaget, J. (1952). The origins of intelligence in children. New York, NY: International University Press.

Ractham, P., \& Firpo, D. (2011). Using social networking technology to enhance learning in higher education: A case study using Facebook. Proceedings of the 44th Hawaii International Conference on System Sciences . 
Savery, J., \& Duffy, T. (1996). Problem based learning: An instructional model and its constructivist framework. In B. Wilson, Constructivist learning environments: Case studies in instructional design. Englewood Cliffs, NJ: Educational Technology Publications.

Short, J., Williams, E., \& Christie, B. (1976). The social psychology of telecommunications. New York, NY: John Wiley \& Sons.

Simon, H. (1996). The sciences of the artificial (3rd ed.). Cambridge, MA: MIT Press.

Smith, A. (2011, June 1). Twitter update 2011. (Pew Research Center) Retrieved July 4, 2011, from http://pewresearch.org/pubs/2007/twitter-users-cell-phone-2011-demographics

Soloway, E., Jackson, S., Klein, J., Quintana, C., Reed, J., Sptulnik, J., \& Scala, N. (1996). Learning theory in practice: Case studies of learner-centered design, pp. 189-196. Conference on Human Factors in Computing Systems.

Song, H., \& Yuen, M. (2008). Educational blogging: A Malaysian university students' perception and experience. Hello! Where are you in the landscape of educational technology? Melbourne, Australia: ASCLITE.

Sorenson, E., \& Takle, E. (2002). Collaborative knowledge building in Web-based learning: Assessing the quality of dialogue. International Journal of E-Learning, 1(1).

Squires, D. (1999). Educational software \& learning: Subversive use \& volatile design. Hawaiian International Conference on System Sciences.

Thoms, B. (2011). A dynamic social feedback system to support learning and social interaction in higher education. IEEE Transactions on Learning Technologies, 4(4), 340-352.

Thoms, B., Garrett, N., \& Ryan, T. (2009). Online learning communities in the new "U”. International. Journal of Networking and Virtual Organisations, 6(5), 499-517.

Tu, C., \& McIsaac, M. (2002). The relationship of social presence and interaction in online classes. The American Journal of Distance Education, 16(3), 131-150.

Twitter. (2011). Official Twitter blog. Retrieved May 24, 2011, from http://blog.twitter.com/2011/03/numbers.html

U.S. Census Bureau. (2009). School enrollment--Social and economic characteristics of students: October 2009. Retrieved July 3, 2011, from http://www.census.gov/population/www/socdemo/school/cps2009.html

Vasileiou, V. N., \& Paraskeva, F. (2010). Teaching role-playing instruction in Second Life: An exploratory study. Journal of Information, Information Technology, and Organizations, 5, 25-50. Retrieved from http://www.jiito.org/articles/JIITOv5p025-050Vasileiou431.pdf

Vygotsky, L. (1987). Mind in society: The development of higher psychological processes. Cambridge, MA: Harvard University Press.

Walls, J. G., Widmeyer, G. R., \& El Sawy, O. A. (1992). Building an information system design theory for vigilant EIS. Information Systems Research, 3(1), 36-59. 


\section{Biography}

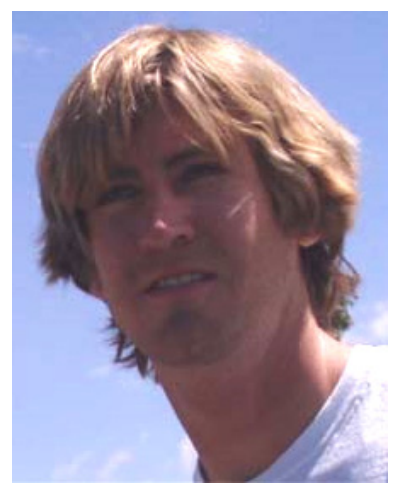

Brian Thoms is Assistant Professor of Computer Systems at the State University of New York, Farmingdale. He received his BS in Computer Science at Fordham University, his MS in Information Systems at Stevens Institute of Technology and his PhD in Information Systems and Technology at Claremont Graduate University. Brian has worked in the IT sector since 1997 providing strategic software solutions on and off Wall Street. Today, his primary research measures the impact of social technologies on learning and interaction within higher education. In 2007, his paper titled, "Resurrecting Graduate Conversation through an Online Learning Community," won the award for Best Research Paper at the IADIS Multi-Conference on Computer Science and Information Systems. Brian is also Chief Software Engineer for HealthATM.com, which provides personal health management for at-risk populations. 